\title{
TU/e EmonOEN

\section{Amorphous hydrogenated silicon films produced by an expanding argon-silane plasma investigated with spectroscopic IR ellipsometry}

\author{
Citation for published version (APA): \\ Wilbers, A. T. M., Meeusen, G. J., Haverlag, M., Kroesen, G. M. W., Schram, D. C., \& Kersten, H. (1991). \\ Amorphous hydrogenated silicon films produced by an expanding argon-silane plasma investigated with \\ spectroscopic IR ellipsometry. Thin Solid Films, 204(1), 59-75. https://doi.org/10.1016/0040- \\ 6090\%2891\%2990494-I, https://doi.org/10.1016/0040-6090(91)90494-I
}

DOI:

10.1016/0040-6090\%2891\%2990494-I

10.1016/0040-6090(91)90494-I

Document status and date:

Published: 01/01/1991

\section{Document Version:}

Publisher's PDF, also known as Version of Record (includes final page, issue and volume numbers)

\section{Please check the document version of this publication:}

- A submitted manuscript is the version of the article upon submission and before peer-review. There can be important differences between the submitted version and the official published version of record. People interested in the research are advised to contact the author for the final version of the publication, or visit the DOI to the publisher's website.

- The final author version and the galley proof are versions of the publication after peer review.

- The final published version features the final layout of the paper including the volume, issue and page numbers.

Link to publication

\footnotetext{
General rights

- You may freely distribute the URL identifying the publication in the public portal. follow below link for the End User Agreement:

www.tue.nl/taverne

\section{Take down policy}

If you believe that this document breaches copyright please contact us at:

openaccess@tue.nl

providing details and we will investigate your claim.
}

Copyright and moral rights for the publications made accessible in the public portal are retained by the authors and/or other copyright owners and it is a condition of accessing publications that users recognise and abide by the legal requirements associated with these rights.

- Users may download and print one copy of any publication from the public portal for the purpose of private study or research.

- You may not further distribute the material or use it for any profit-making activity or commercial gain

If the publication is distributed under the terms of Article 25fa of the Dutch Copyright Act, indicated by the "Taverne" license above, please 


\section{AMORPHOUS HYDROGENATED SILICON FILMS PRODUCED BY AN EXPANDING ARGON-SILANE PLASMA INVESTIGATED WITH SPECTROSCOPIC IR ELLIPSOMETRY}

A. T. M. WILBERS, G. J. MEEUSEN, M. HAVERLAG, G. M. W. KROESEN AND D. C. SCHRAM Eindhoven University of Technology, Physics Department, P.O. Box 513, 5600 MB Eindhoven (The Netherlands)

H. KERSTEN

Ernst-Moritz-Arndt Universität Greifswald, Section Physics/Electronics, 2200 Greifswald (F.R.G.)

(Received September 14, 1990; revised December 7, 1990; accepted February 25, 1991)

We have produced amorphous hydrogenated silicon (a-Si:H) films from silane with an unconventional deposition technique, a supersonically expanding d.c. arc plasma. The deposited films are analysed mainly by using spectroscopic IR ellipsometry. Further analysis has been performed with scanning electron microscopy, IR absorption spectroscopy and in situ He-Ne ellipsometry. The film structure appears to be strongly linked to the degree of ionization of the expanding beam, the injection location of silane gas, the degree of dissociation and the percentage of the injected hydrogen gas. Deposition at low arc power results in films of polysilane, which are very sensitive to oxidation during air exposure. Without hydrogen injection, films with a high refractive index and low hydrogen content are obtained (below the detection limit of the IR transmission spectrometer). Hydrogen injected in the middle of the plasma arc results in a-Si:H films with a refractive index of 3.75 at $632 \mathrm{~nm}$; this value is close to the indices of the best films obtained with plasma-enhanced chemical vapour deposition (PECVD). In these films, the strength of the vibrational absorption at $2000 \mathrm{~cm}^{-1}$, which can be assigned to $\mathrm{SiH}$ stretch bonds, is equal to the strength of a vibrational absorption at $2085 \mathrm{~cm}^{-1}$. Because the bending absorptions of $\mathrm{SiH}_{2}$ at 860 and $890 \mathrm{~cm}^{-1}$ are not detected in the films produced, it is concluded that this $2085 \mathrm{~cm}^{-1}$ absorption peak in our films is caused by bond stretching of $\mathrm{SiH}$ rather than by that of $\mathrm{SiH}_{2}$.

As in PECVD, the optimum substrate temperature at which films of good quality are obtained is in the range from 525 to $575 \mathrm{~K}$.

The deposition rate is of the order of several nanometers per second.

\section{INTRODUCTION}

The deposition of thin films of hydrogenated amorphous silicon $(\mathrm{a}-\mathrm{Si}: \mathrm{H})$ is one of the steps in the production of devices such as solar cells or large liquid crystal displays. Common deposition techniques are chemical vapour deposition (CVD), plasma-enhanced CVD (PECVD), photon-enhanced CVD and sputtering ${ }^{1}$. The 
PECVD technique is used in nearly all technological applications where a high quality semiconductor material is desired, whereas the other techniques are applied in more exploratory research. The deposition rate is typically in the nanometer per second range or smaller.

We have produced the a-Si:H films with a supersonically expanding d.c. arc plasma. This deposition system is based on a principle which was used first to deposit carbon-based films ranging from diamond to graphite and polymer-like carbon $^{2}$. In that system deposition rates of $200 \mathrm{~nm} \mathrm{~s}^{-1}$ were achieved over large areas $\left(100 \mathrm{~cm}^{2}\right)$ for polymer-like and diamond-like carbon films $\mathrm{s}^{3,4}$ and $600 \mathrm{~nm} \mathrm{~s}^{-1}$ for graphite films (small areas, several square centimetres) ${ }^{5}$. This new method is based on the geometrical separation of production and transport of the particles which are used in the deposition process. In a thermal argon plasma with a temperature of approximately $1 \mathrm{eV}$, the injected molecules are dissociated and ionized. In the resulting supersonic expansion, the particles are transported towards the substrate. The particles are usually atoms, ions and fragments of molecules. The substrate can be heated or cooled or a bias voltage can be applied. The energy of the argon ions which arrive at the surface of the substrate is of the order of $1 \mathrm{eV}$. Because the ion energy in the present deposition technique is substantially lower than the value in an r.f. plasma $(30 \mathrm{eV})^{6}$, it is expected that no argon is incorporated in the films.

Analysis of the carbon films produced by the method described above with techniques such as Raman scattering, Auger electron spectroscopy, X-ray photoelectron spectroscopy, Rutherford backscattering and visible spectroscopic ellipsometry ${ }^{7}$ showed that in spite of the high deposition rate the quality was good.

The aim of the present paper is to present the IR ellipsometric results on the first a-Si:H films obtained in a new specific silane deposition apparatus in which the above-mentioned deposition technique is used. The study of a-Si:H can be carried out with various techniques. In several review articles and books ${ }^{8-12}$ techniques such as extended $\mathrm{X}$-ray absorption fine structure, nuclear magnetic resonance, core level X-ray photoemission spectroscopy, visible spectroscopic ellipsometry, photoconductivity, dark conductivity and IR absorption spectroscopy are discussed. Research has shown ${ }^{8-12}$ that the concentration of hydrogen in the films and the way it is bound to the silicon atoms are related to the electronic properties of the films.

IR absorption spectroscopy is well suited to detect and distinguish between the various silicon hydride groups. The technique which is normally used to measure the absorption bands of silicon hydrides is transmission spectroscopy. A disadvantage of this technique is the need for thick films (typically in the order of microns). We used spectroscopic ellipsometry to investigate the absorption due to the stretching vibrations of the $\mathrm{SiH}$ and other silicon-hydrogen bonds. The advantage of this method, compared with transmission spectroscopy, is the ability to analyse thin films. The thickness may range from several nanometres up to several microns. Drevillon et al. ${ }^{13,14}$ used this technique to analyse ultrathin films. As mentioned above, so far we have only investigated the stretching vibrations. The vibrations due to the wagging, rocking or bending of the bonds between silicon and hydrogen are located in a wavenumber range which is outside the responsivity range of the currently used system $\left(1100 \mathrm{~cm}^{-1}-4000 \mathrm{~cm}^{-1}\right)$. As well as information on the 
stretching vibrations, the ellipsometer can also be used to measure the pseudo index of refraction, the absorption coefficient and the thickness of the film under study. Pseudo refractive indices are used in analogy with the pseudo dielectric function ${ }^{15}$.

We shall briefly discuss the deposition apparatus and the spectroscopic ellipsometer used. Then the results are presented for the first films produced with the deposition system. Finally we discuss these results.

\section{EXPERIMENT}

In Fig. 1 the deposition apparatus is depicted schematically. The vacuum chamber is a cylindrical vessel $(1.15 \mathrm{~m}$ in length and $0.5 \mathrm{~m}$ in diameter) with a substrate support at one end. The substrate support extends $0.5 \mathrm{~m}$ into the vacuum vessel. The axial length of the vacuum vessel can be reduced to $0.8 \mathrm{~m}$ by removing a ring of $0.35 \mathrm{~m}$ length. The substrate support can be heated and the temperature is measured by thermocouples. The substrate holder is not heated significantly by the plasma beam. An increase of $20 \mathrm{~K}$ occurred after 5 min with a plasma current of $40 \mathrm{~A}$. The system is pumped by a series of two Roots blowers and a rotary pump (pumping speed $2600 \mathrm{~m}^{3} \mathrm{~h}^{-1}$ ). A large turbomolecular pump is used to maintain high vacuum $\left(10^{-4} \mathrm{~Pa}\right)$ when no deposition takes place. At the other end of the cylindrical vessel, a wall-stabilized d.c. arc is mounted. In this wall-stabilized arc, a thermal argon plasma is produced at about $12000 \mathrm{~K}$ and $4 \times 10^{4} \mathrm{~Pa}(0.4 \mathrm{bar})$. The precise values of the temperature and pressure depend on the current and the gas flow through the arc. The arc consists of three cathodes and an anode separated by a stack of electrically isolated copper plates. The construction of this arc is treated in detail in Kroesen et al. ${ }^{16}$ The argon carrier plasma is allowed to expand supersonically in the vacuum vessel through a conically shaped hole in the anode. In the arc, the gas is accelerated to sonic velocity in the anode (nozzle) followed by a supersonic expansion. After several centimetres a shock occurs: the velocity of the plasma is reduced to a subsonic level. The subsonic beam reaches the substrate with a velocity of approximately $1000 \mathrm{~m} \mathrm{~s}^{-1}$ and with a temperature of about $2000 \mathrm{~K}$.

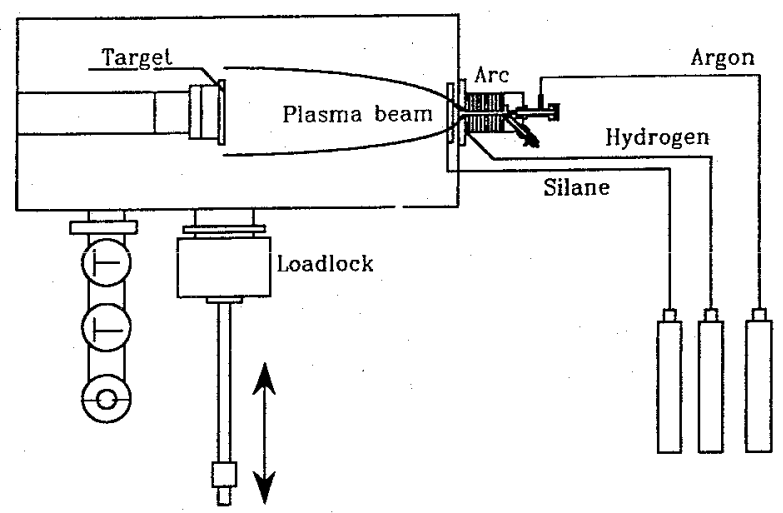

Fig. 1. Schematic view of the silicon deposition apparatus. The gas cylinders as well as the Roots pumps system are located in a dedicated building outside the laboratory. The complete deposition apparatus is computer controlled. 
Just outside the nozzle an argon-silane (10:1) mixture is injected into the beam. Because of the high temperature and high electron density of the expanding plasma beam, the silane is dissociated and partially ionized. In the arc, just before the nozle, a hydrogen flow can be injected into the plasma.

The substrate support consists of a fixed part with a heater and a removable part on which the substrates are mounted. The latter part is used to insert the substrates into the vacuum system through a load lock. The load lock is pumped with a turbomolecular pump. The load lock is used to prevent contamination of the vacuum system with oxygen, nitrogen and water. When the samples are taken in or out of the load lock system, the load lock system is vented with high purity argon.

The substrate support is designed to hold one large wafer of $10 \mathrm{~cm}$ diameter or 'five different samples of $2.5 \mathrm{~cm}$ diameter. We used quartz, gold-coated quartz, goldcoated copper, gold-coated steel, stainless steel, silver and crystalline silicon substrates for our deposition experiments. Although gold is known to form silicides, we used it for its good IR reflectance. The diffusion length of gold into silicon films is at temperatures below $700 \mathrm{~K}$ smaller than $0.5 \mathrm{~nm}^{17}$. This is negligible compared with the thicknesses of the films produced. In Table I, a short overview is given of the experimental sețtings used in our experiments. More detailed information concerning the silicon deposition apparatus can be found in ref. 18 .

\section{TABLE I}

A SHORT OVERVIEW OF THE EXPERIMENTAL SETTINGS

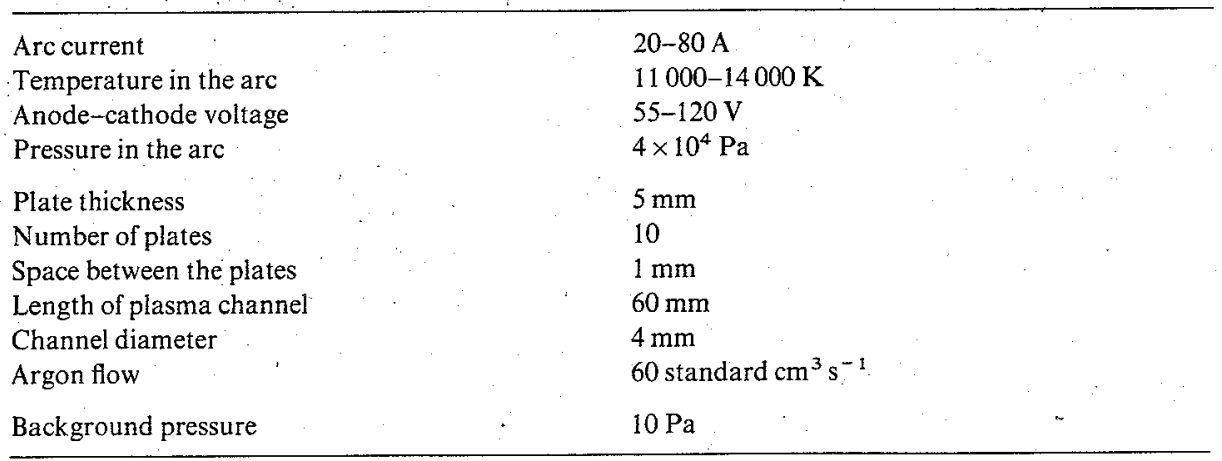

\section{SPECTROSCOPIC ELLIPSOMETER}

The spectroscopic ellipsometer is shown in Fig. 2. Detailed information about the ellipsometer can be found in refs. 19 and 20 . The light source used in this ellipsometer is a cascade arc. The use of this arc enables us to use the ellipsometer from $200 \mathrm{~nm}$ to $8.5 \mu \mathrm{m}$ owing to the high brightness (thermal plasma of $13500 \mathrm{~K}$; pressure, $\left.4.5 \times 10^{5} \mathrm{~Pa}\right)^{21}$. The light emitted by the arc is not polarized. The polarizers are $\mathrm{MgF}_{2}$ Rochon prisms. The ellipsometer is placed in a dry-air-filled box to eliminate water and carbon dioxide absorptions. These absorptions could otherwise hamper measurements in certain wavelength ranges. 
Essentially, the ellipsometer measures the effect of a thin layer on the complex ratio $\rho$ of the reflection coefficients $r_{\mathrm{p}}$ and $r_{\mathrm{s}}$ of light polarized parallel and perpendicular respectively to the plane of incidence:

$$
\rho=r_{\mathrm{p}} / r_{\mathrm{s}}
$$

Because only the ratio is measured, the ellipsometer is relatively insensitive to absorption in the light path. This ratio can also be expressed as

$$
\rho=\tan \Psi e^{\mathrm{i} A}
$$

where $\Psi$ and $\Delta$ are the well-known ellipsometric angles. These $\Psi$ and $\Delta$, which are obtained during an ellipsometric measurement, can be related to the physical parameters $n$ (complex index of refraction) and $d$ (thickness) of the layer. If the layer

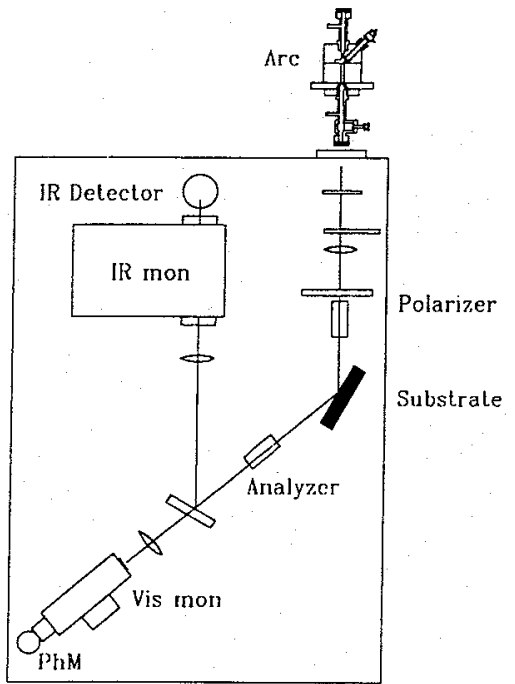

Fig. 2. Schematic view of the spectroscopic ellipsometer. The polarizer rotates with a frequency of $30 \mathrm{~Hz}$ The analyser is set an an agle of $45^{\circ}$ with respect to the plane of incidence. The IR detector is an InSb-MCT detector which operates from 2.5 to $8.5 \mu \mathrm{m}$. The detector at the visible monochromator is a photomultiplier.

is not transparent (i.e. the impinging radiation does not reach the substrate), $n$ can be easily calculated from $\Psi$ and $\Delta$ (semi-infinite layer). This is only valid if the influence of surface roughness and top layers is small. If the layer becomes transparent, we used a model described in ref. 19 to obtain from $\Psi$ and $\Delta$ the complex index of refraction $n$ and the thickness $d$ of the layer by simulation of the measured spectra: In the case of a transparent film, the impinging iight beam reaches the substrate. After reflection at the substrate-film interface, interference occurs with directly reflected light. Spectral modulations start to occur in $\psi$ and $\Delta$. If the pseudo index of refraction $n$ is calculated directly from this $\Psi$ and $\Delta$ using the formula for a semiinfinite substrate, $n$ is also modulated. An example is shown in Fig. 3. From the distance between the interference peaks and the extrapolation of the pseudo index of 
refraction, a fast estimation of the thickness can be obtained:

$$
d=(h c / 2 n \mathrm{~d} E)\left(1-\sin ^{2} \phi_{0} / n^{2}\right)^{1 / 2}
$$

where $\mathrm{d} E$ is the energy difference between two interference peaks, $\phi_{0}$ the angle of incidence, $h$ Planck's constant and $c$ the velocity of light. This estimation of the thickness from the visible measurements is used in the simulation of the spectral interference of $\Delta$ in the IR. With this simulation accurate values of $d$ and $n$ can be deduced from the IR measurements.

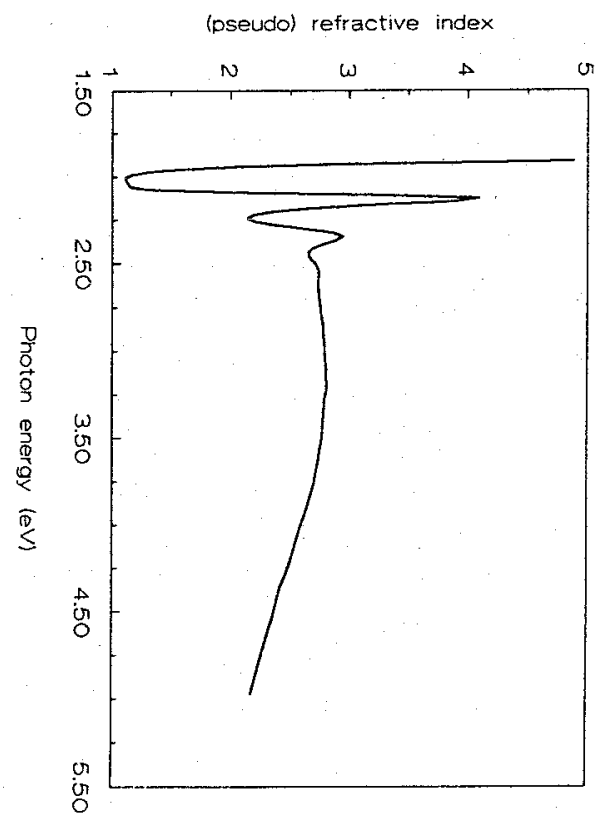

Fig. 3. The pseudo index of refraction as a function of the photon energy calculated with the assumption that the film is not transparent. It is clear that this assumption is not valid below $2.5 \mathrm{eV}$.

IR vibrational absorptions in the film are represented as peaks in $\Psi$. The magnitudes of these peaks in $\Psi$ depend on the slope of $\Delta$ and on the film thickness. The signs of these peaks can be either positive or negative. If an absorption is located at a maximum in the interference pattern of $\Delta$ no peak in $\Psi$ can be observed. For convenience, we choose to show all peaks in $\Psi$ in Fig. 5 in the negative direction. The vibrational absorptions can be characterized by a harmonic oscillator strength and a width. The oscillator strength is calculated by simulation of the measurements using the following expression for the dielectric function:

$$
\varepsilon_{\mathrm{r}}(\omega)=\varepsilon_{\infty}+\sum_{i} \frac{f_{i} \omega_{0 i}{ }^{2}}{\omega_{0 i}{ }^{2}-\omega^{2}+i \tau_{\mathrm{i}} \omega}
$$

where $\varepsilon_{r}(\omega)$ is the complex dielectric function, $\varepsilon_{\infty}$ the continuum contributions to the dielectric function, $f_{i}$ the oscillator strength of a vibrational absorption, $\tau_{i}$ the width 
of the peak, $\omega_{0 i}$ the frequency of this vibrational absorption and $\omega$ the frequency. The oscillator strength is defined here as

$$
f_{i}=\frac{N_{i} e^{* 2}}{\varepsilon_{0} m \omega_{0}^{2}}
$$

where $N_{i}$ is the number of oscillators per volume, $e^{*}$ is the effective charge of the oscillator, $\varepsilon_{0}$ is the permittivity of vacuum, $m$ the reduced mass of the oscillator and $\omega_{0}$ the frequency of the oscillator. A measurement and simulation of several IR vibrational absorptions are shown in Fig. 4.

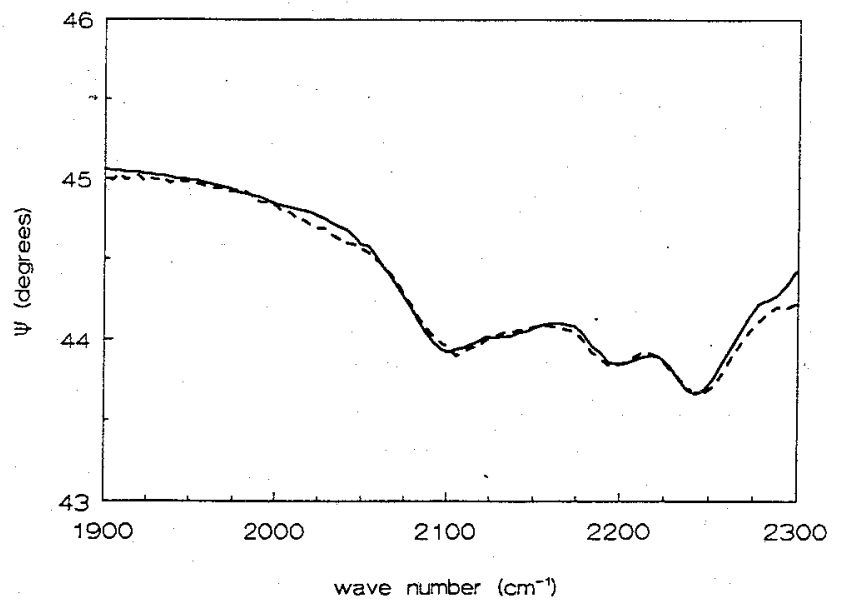

Fig. 4. A measurement (--) and simulation (-) of several IR vibrational absorptions expressed in $\Psi$. The measurement represents sample 35 .

\section{RESULTS AND DISCUSSION}

The samples which are analysed are the first a-Si:H samples produced with our deposition technique. We varied four of the experimental conditions: substrate temperature, the distance between substrate and arc, arc current and hydrogen flow. The other experimental conditions were kept constant. The pressure inside the arc at the cathode side was about $4 \times 10^{4} \mathrm{~Pa}$. The argon flow through the arc was 60 standard $\mathrm{cm}^{3} \mathrm{~s}^{-1}$. A small flow of 0.3 standard $\mathrm{cm}^{3} \mathrm{SiH}_{4} \mathrm{~s}^{-1}$ in 3 standard $\mathrm{cm}^{3}$ argon $\mathrm{s}^{-1}$ was injected into the expanding beam. The background pressure in the deposition chamber was $10 \mathrm{~Pa}$.

We performed five series of experiments. The deposition parameters were changed in order to vary the degree of dissociation of the silane gas, the substrate temperature and the concentration and degree of dissociation of molecular hydrogen. In the case of a pure argon plasma, the degree of ionization of the plasma is between $1 \%$ and $10 \%$ depending on the current through the arc. In the expansion zone, the degree of ionization is approximately homogeneous throughout the plasma if no additional gases are injected ${ }^{22}$. The first part of the expansion is supersonic. The temperature is lowered from approximately $1 \mathrm{eV}$ to $0.5 \mathrm{eV}$ (exact 
values depend on the current through the arc). After several centimetres a shock occurs and the plasma is heated again. After the shock the plasma beam expands subsonically with slowly decreasing density $\left(10^{19} \mathrm{~m}^{-3}\right)$, velocity $\left(1000 \mathrm{~m} \mathrm{~s}^{-1}\right)$ and temperature (1500-3000 K) in the case of a pure argon beam. The time of flight from arc to substrate is about $1 \mathrm{~ms}$. The seed gases can be injected in three locations; in the arc, in the nozzle and in the expansion zone. In the first two, the available energy is the highest. However, immediate complete dissociation of the silane occurs which can be followed by deposition there and obstruction of the injector. This cannot be permitted in view of the safety precautions. If silane gas is injected into the subsonic zone of the expansion after the shock, this disadvantage of possible obstruction is not present as the pressure is much lower. Several dissociation paths are available; (dissociative) charge exchange with argon ions followed by dissociative recombination, vibrational excitation by ions and hot atoms followed by dissociation, excitation by vacuum UV radiation emitted by the arc and the dissociation paths involving electrons. In the travelling subsonic beam, successive interaction with argon ions and atoms can dissociate the silane to $\mathrm{SiH}_{3}, \mathrm{SiH}_{3}$ to $\mathrm{SiH}_{2}$ and so on until no ions or atoms are available or the silane is completely dissociated.

The first series of experiments was devoted to investigating the influence of the substrate temperature. In CVD techniques, the substrate temperature at which the optimum a-Si:H is produced is between $500 \mathrm{~K}$ and $600 \mathrm{~K}$. Our temperature scan ranged from room temperature to $625 \mathrm{~K}$. The distance between the arc and the substrate support was $0.85 \mathrm{~m}$ and the arc current was $30 \mathrm{~A}$. In Fig. 5 the absorption peaks in the ellipsometric angle $\Psi$ are shown for samples produced at substrate

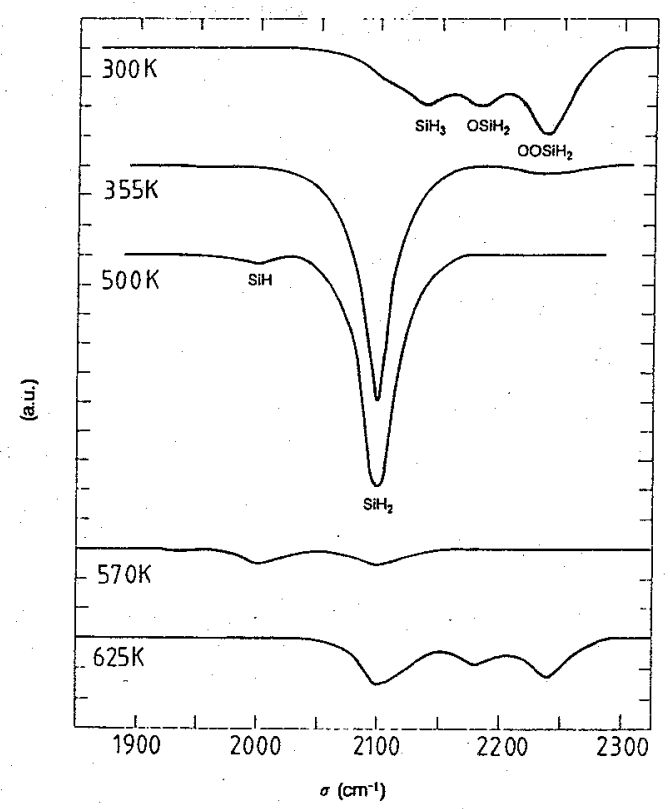

Fig. 5. The ellipsometric angle $\Psi$ as a function of the wavenumber. The absorptions show as peaks in $\Psi$. The substrate temperature has been changed from room temperature to $625 \mathrm{~K}$. The temperatures are indicated in the figure. 
temperatures of $300,355,500,570$ and $625 \mathrm{~K}$. Five different IR vibrational absorption peaks are observed. In Table II the oscillator strengths of the peaks in Fig. 5 are given together with the refractive indices (calculated in the IR region from 1850 to $2350 \mathrm{~cm}^{-1}$ ) and deposition rates of the films. In Fig. 5 , the peaks at $570 \mathrm{~K}$ of the IR vibrational absorption at a frequency of $2100 \mathrm{~cm}^{-1}$ are much smaller than the peaks at 355 and $500 \mathrm{~K}$. However, the strength of the $2100 \mathrm{~cm}^{-1}$ peak at $570 \mathrm{~K}$ is $6 \times 10^{-3}$ and the strength of this peak at $500 \mathrm{~K}$ is only $5 \times 10^{-3}$.

TABLE II

OSCILLATOR STRENGTHS, PSEUDO REFRACTIVE INDICES AND DEPOSITION RATES AS A FUNCTION OF SUBSTRATE TEMPERATURE

\begin{tabular}{|c|c|c|c|c|c|c|c|c|}
\hline \multirow[t]{2}{*}{ Sample } & \multirow{2}{*}{$\begin{array}{l}T \\
(\mathrm{~K})\end{array}$} & \multicolumn{5}{|c|}{ Oscillator strengths of the following peaks $\left(\times 10^{-4}\right)$} & \multirow{2}{*}{ Index } & \multirow{2}{*}{$\begin{array}{l}\text { Rate } \\
\left(\mathrm{nm} \mathrm{s}^{-1}\right)\end{array}$} \\
\hline & & $\begin{array}{l}2000 \\
\mathrm{~cm}^{-1} \\
\mathrm{SiH}\end{array}$ & $\begin{array}{l}2100 \\
\mathrm{~cm}^{-1} \\
\mathrm{SiH}_{2}\end{array}$ & $\begin{array}{l}2140 \\
\mathrm{~cm}^{-1} \\
\mathrm{SiH}_{3}\end{array}$ & $\begin{array}{l}2180 \\
\mathrm{~cm}^{-1} \\
\mathrm{OSiH}_{2}\end{array}$ & $\begin{array}{l}2240 \\
\mathrm{~cm}^{-1} \\
\mathrm{OOSiH}_{2}\end{array}$ & & \\
\hline 10 & 300 & - & 12 & 12 & 10 & 14 & 1.73 & - \\
\hline $11 \mathrm{~b}$ &. .355 & - & 84 & - & - & - & 2.1 & 18 \\
\hline $12 \mathrm{a}, 1$ & 500 & 3.5 & 50 & - & - & - & 2.0 & 5 \\
\hline $12 a, 2$ & & 1 & 12 & 7 & 6 & 22 & & \\
\hline $20 \mathrm{a}$ & 570 & 14 & 60 & 10 & - & - & 2.1 & 5.5 \\
\hline 16 & 625 & - & 20 & 7 & 8 & 14 & 2.0 & 6 \\
\hline
\end{tabular}

This seeming discrepancy between the height of the peaks in $\Psi$ and the actual oscillator strength is due to the interference in the film, which is expressed by the sinusoidal modulation of the ellipsometric angle $\Delta$ as can be seen in Fig. 3 in the higher wavelength region (above $550 \mathrm{~nm}$ ) and which extends into the IR. If the slope of $\Delta$ is strong, the peaks in $\Psi$ are also strong. If the slope is small, e.g. in the maxima and minima of the interference, the peak in $\Psi$ is also small. The absorption peak at a frequency of $2000 \mathrm{~cm}^{-1}$, which is attributed to a stretch mode of $\mathrm{SiH}^{7}$, occurs only at a substrate temperature at and above $500 \mathrm{~K}$ and increases slightly at a substrate temperature of $570 \mathrm{~K}$. At lower or higher temperatures, a vibrational absorption at $2000 \mathrm{~cm}^{-1}$ cannot be distinguished. The absorption peak at a frequency of $21.00 \mathrm{~cm}^{-1}$ which is present in all samples is attributed to a stretching mode of $\mathrm{SiH}_{2}{ }^{7}$. At $570 \mathrm{~K}$ this peak is of the same order as the SiH peak. Additional peaks at 2140,2180 and $2240 \mathrm{~cm}^{-1}$ occur at the lowest and highest temperature. The peak at $2140 \mathrm{~cm}^{-1}$ is due to $\mathrm{SiH}_{3}$ or chains of $\mathrm{SiH}_{2}$ (polysilane) ${ }^{8}$. The vibrational absorptions at 2180 and $2240 \mathrm{~cm}^{-1}$ are shifted absorption peaks of the stretch mode of $\mathrm{SiH}_{2}$. If one oxygen atom is bound to the $\mathrm{SiH}_{2}$ molecule, the peak shifts to $2180 \mathrm{~cm}^{-1}$ and two oxygen atoms shift the absorption at a frequency $2100 \mathrm{~cm}^{-1}$ to $2240 \mathrm{~cm}^{-1}$ (ref. 8 ). The samples are apparently strongly oxidized. To check whether the other samples are sensitive to oxidation, the analysis was repeated after several days and after one month. It şhowed that the samples produced at 355 and $500 \mathrm{~K}$ also oxidized. In Table II, this is shown for the $500 \mathrm{~K}$ sample (sample 12a). The oscillator strength of the $\mathrm{SiH}_{2}$ decreases strongly and peaks appear at 2140, 2180 and $2240 \mathrm{~cm}^{-1}$ of comparable strengths. Only the sample produced at $570 \mathrm{~K}$ 
remained stable, even after one month. These results suggest that the samples produced at temperatures lower than $500 \mathrm{~K}$ or higher than $625 \mathrm{~K}$ have an open structure with many large voids. This would explain the rapid and strong oxidation. The samples produced at $355 \mathrm{~K}$ had a deposition rate of $20 \mathrm{~nm} \mathrm{~s}^{-1}$. This rate decreased rapidly to $6 \mathrm{~nm} \mathrm{~s}^{-1}$ at $500 \mathrm{~K}$. The deposition rate remained almost stable with further temperature increase with a deposition rate of $5.5 \mathrm{~nm} \mathrm{~s}^{-1}$ at $570 \mathrm{~K}$ and $6 \mathrm{~nm} \mathrm{~s}^{-1}$ at $625 \mathrm{~K}$. The pseudo index of refraction remained low, between 1.7 and 2.1. These values also indicate a rather open structure or a rough surface.

The subsequent experiments were carried out at a fixed temperature of $550 \mathrm{~K}$. As shown by the temperature scan, a film containing $\mathrm{SiH}$ is produced at this temperature. Also, at this temperature the films do not oxidize.

In the next experiments, the arc current and the distance from arc to substrate have been varied. A hydrogen flux is also introduced. First, we varied the arc current from $20 \mathrm{~A}$ to $60 \mathrm{~A}$. The other experimental conditions were kept constant. With increasing current the temperature of the argon gas and the degrce of ionization of the argon plasma increase, thereby enhancing the dissociation degree of silane. In Table III the oscillator strengths, pseudo refractive indices and deposition rates of the samples produced at 20,40 and $60 \mathrm{~A}$ are shown. At $20 \mathrm{~A}$, vibrational absorptions at frequencies of 2000 and $2100 \mathrm{~cm}^{-1}$ occur. Also, small absorptions due to oxidation are visible. At $40 \mathrm{~A}$, only small absorption peaks at frequencies of 2000 and $2100 \mathrm{~cm}^{-1}$ are present. From the samples produced at $60 \mathrm{~A}$ no peaks at all could be measured.

A measurement with a Bruker IR transmission interferometer showed that the hydrogen content was below the detection limit of this interferometer $(1 \mathrm{~nm}$ thick film). No vibrational absorptions of $\mathrm{SiH}_{n}$ could be detected in the range from 3000 to $400 \mathrm{~cm}^{-1}$. From the table, an apparent increase in the strength of the $\mathrm{SiH}$ peak with the arc current and an apparent decrease in the strength of the $\mathrm{SiH}_{2}$ peak can be seen.

\section{TABLE III}

OSCILLATOR STRENGTHS, PSEUDO REFRACTIVE INDICES AND DEPOSITION RATES

\begin{tabular}{|c|c|c|c|c|c|c|c|c|}
\hline \multirow[t]{2}{*}{ Sample } & \multirow{2}{*}{$\begin{array}{l}I \\
\text { (A) }\end{array}$} & \multicolumn{5}{|c|}{ Oscillator strengths of the following peaks $\left(\times 10^{-4}\right)$} & \multirow[t]{2}{*}{ Index } & \multirow{2}{*}{$\begin{array}{l}\text { Rate } \\
\left(\operatorname{lnm}_{\sim} s^{-1}\right)\end{array}$} \\
\hline & & $\begin{array}{l}2000 \\
\mathrm{~cm}^{-1} \\
\mathrm{SiH}\end{array}$ & $\begin{array}{l}2100 \\
\mathrm{~cm}^{-1} \\
\mathrm{SiH}_{2}\end{array}$ & $\begin{array}{l}2140 \\
\mathrm{~cm}^{-1} \\
\mathrm{SiH}_{3}\end{array}$ & $\begin{array}{l}2180 \\
\mathrm{~cm}^{-1} \\
\mathrm{OSiH}_{2}\end{array}$ & $\begin{array}{l}2240 \\
\mathrm{~cm}^{-1} \\
\mathrm{OOSiH}_{2}\end{array}$ & & \\
\hline 22 & 20 & 1 & 25 & - & 2 & 5 & 2.0 & 18 \\
\hline 23 & 40 & 3 & 5 & - & - & - & 2.0 & 7 \\
\hline 24 & 60 & - & - & - & - & - & 3.7 & 2 \\
\hline
\end{tabular}

The pseudo index of refraction increases from 2 to 3.7. The maximum value is 3.7 for the sample produced at an arc current of $60 \mathrm{~A}$ and should be above $3.4^{10}$. The deposition rate was in the range from 2 to $18 \mathrm{~nm} \mathrm{~s}^{-1}$, decreasing with increasing current. The surface roughness decreases considerably when the current is increased. In Fig. 6 a scanning electron microscopy (SEM) micrograph of the sample with a refractive index at $5 \mu \mathrm{m}$ of 3.7 is shown. The surface structure which is cauliflower 
like is typical for amorphous film growth ${ }^{23,24}$. This refractive index suggests a low hydrogen content as it approaches the value for amorphous silicon ${ }^{10}$.

To enhance the hydrogen content, a hydrogen flow is injected into the arc channel just before the arc expands into the vacuum vessel. We varied the arc current from 20 to $80 \mathrm{~A}$. However, admixing of hydrogen has also a dramatic effect on the degree of ionization of the plasma. Injection of hydrogen in the middle of the plasma channel lowers the electron density in the expansion at $30 \mathrm{~cm}$ from the anode by several orders of magnitude as has become clear from other experiments. Possible reasons for this dramatic loss of electrons compared with the pure argon case are charge exchange with vibrationally excited molecules followed by dissociative recombination and dissociative attachment ${ }^{21}$. If ions and electrons have an important role in the deposition process then the properties of the films and the deposition rate could be changed also by this effect. Injection of hydrogen in the anode at the end of the plasma arc should lower the degree of ionization of the plasma even more, because the heating of the molecular hydrogen and dissociation then take place in the afterglow region of the plasma and will be not complete.

One of the possible expected side effects of hydrogen is an etching of the hydrogen attached to $\mathrm{SiH}_{n}$ on the growing surface. The deposition rate is expected to be higher as a result of this effect. Also, direct incorporation of the hydrogen in the films is possible.

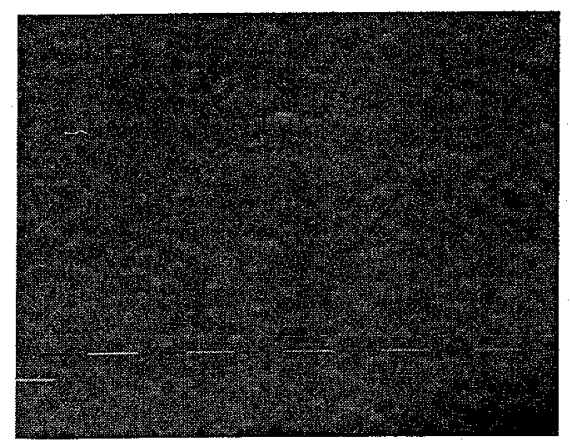

Fig. 6. SEM micrograph of sample 24. The white bar represents $1 \mu \mathrm{m}$.

In Table IV the oscillator strengths, the refractive indices and deposition rates are shown for the different currents. Compared with the previous series with no hydrogen flow, significant changes occur. The surface roughness is smaller. Surface analysis with SEM revealed no surface structure at a magnification of $10000 \times$ for all samples in this series. The absorption peak at $2100 \mathrm{~cm}^{-1}$ first increases with increasing current and then remains constant. The peak at $2000 \mathrm{~cm}^{-1}$ decreases with increasing current. In general, the dependence on the current of the plasma is reversed.

The spectra exhibit no trace of oxidation (presence of 2180 and $2240 \mathrm{~cm}^{-1}$ peaks) and only a small vibrational absorption peak of $\mathrm{SiH}_{3}\left(2140 \mathrm{~cm}^{-1}\right)$ for the sample produced with an arc current of $80 \mathrm{~A}$. The pseudo index of refraction of the sample produced at $20 \mathrm{~A}$ is in the range of refractive indices of a-Si:H in the $\mathrm{IR}^{10}$. It has a value of 3.2 . 
TABLE IV

OSCILLATOR STRENGTHS, REFRACTIVE INDICES AND DEPOSITION RATES: A HYDROGEN FLOW IS INJECTED INTO THE EXPANDING BEAM

\begin{tabular}{|c|c|c|c|c|c|c|c|c|}
\hline \multirow[t]{2}{*}{ Sample. } & \multirow{2}{*}{$\begin{array}{l}I \\
(\mathrm{~A})\end{array}$} & \multicolumn{5}{|c|}{ Oscillator strengths of the following peaks $\left(\times 10^{-4}\right)$} & \multirow[t]{2}{*}{ Index } & \multirow{2}{*}{$\begin{array}{l}\text { Rate } \\
\left(\mathrm{nm} \mathrm{s}^{-1}\right)\end{array}$} \\
\hline & & $\begin{array}{l}2000 \\
\mathrm{~cm}^{-1} \\
\mathrm{SiH}\end{array}$ & $\begin{array}{l}2100 \\
\mathrm{~cm}^{-1} \\
\mathrm{SiH}_{2}\end{array}$ & $\begin{array}{l}2140 \\
\mathrm{~cm}^{-1} \\
\mathrm{SiH}_{3}\end{array}$ & $\begin{array}{l}2180 \\
\mathrm{~cm}^{-1} \\
\mathrm{OSiH}_{2}\end{array}$ & $\begin{array}{l}2240 \\
\mathrm{~cm}^{-1} \\
\mathrm{OOSiH}_{2}\end{array}$ & & \\
\hline 25 & 20 & - & - & - & - & - & 3.2 & 1.5 \\
\hline 26 & 40 & 30 & 30 & - & - & - & 2.9 & 2.5 \\
\hline 27 & 60 & 20 & 10 & - & - & - & 2.4 & 5.3 \\
\hline 28 & 80 & 10 & 70 & 2 & - & - & 2.4 & 5.2 \\
\hline
\end{tabular}

The deposition rate is, compared with the previous series, generally lower, only $2 \mathrm{~nm} \mathrm{~s}^{-1}$. With increasing current (equivalent to the ionizing and dissociating power of the expanding plasma beam) the deposition rate increases at first from 1.5 to $5.3 \mathrm{~nm} \mathrm{~s}^{-1}$ and then remains constant.

To increase the deposition rate, we changed the distance from the arc to the substrate support from $0.85 \mathrm{~m}$ to $0.5 \mathrm{~m}$. Again the arc current was changed between 20 and $80 \mathrm{~A}$. In Table $\mathrm{V}$ the oscillator strengths, the pseudo refractive indices and the deposition rates are shown. At $20 \mathrm{~A}$, the strengths of the vibrational absorptions of $\mathrm{SiH}$ and $\mathrm{SiH}_{2}$ are almost equal. At the higher currents, the strength of the $\mathrm{SiH}_{2}$ stretch mode, the pseudo refractive index and the deposition rate are not clearly dependent on the current through the arc. Compared with the previous series of measurements, at the arc-substrate distance of $0.85 \mathrm{~m}$, the surface roughness increases. In Fig. 7 an example is shown (sample 35). The reduction in distance clearly resulted in films of lower refractive indices and higher strengths of the $\mathrm{SiH}_{2}$ vibrational absorptions. The explanation of this effect requires further experiments and experimental data on flux densities of radicals, electrons and ions.

To test whether the $\mathrm{SiH}$ peaks of sample 32 increases with increasing thickness, i.e. the $\mathrm{SiH}$ molecules are located in the bulk and not only on the surface, we have repeated that deposition experiment with a deposition time of $15 \mathrm{~min}$. The sample

TABLE V

OSCILLATOR STRENGTHS, REFRACTIVE INDICES AND DEPOSITION RATES: THE DISTANCE BETWEEN ARC EXIT AND THE SUBSTRATE SUPPORT HAS BEEN REDUCED TO $0.5 \mathrm{~m}$

\begin{tabular}{|c|c|c|c|c|c|c|c|c|}
\hline \multirow[t]{2}{*}{ Sample } & \multirow{2}{*}{$\begin{array}{l}I \\
(\mathrm{~A})\end{array}$} & \multicolumn{5}{|c|}{ Oscillator strengths of the following peaks $\left(\times 10^{-4}\right)$} & \multirow[t]{2}{*}{ Index } & \multirow{2}{*}{$\begin{array}{l}\text { Rate } \\
\left(\mathrm{nm} \mathrm{s}^{-1}\right)\end{array}$} \\
\hline & & $\begin{array}{l}2000 \\
\mathrm{~cm}^{-1} \\
\mathrm{SiH}\end{array}$ & $\begin{array}{l}2100 \\
\mathrm{~cm}^{-1} \\
\mathrm{SiH}_{2}\end{array}$ & $\begin{array}{l}2140 \\
\mathrm{~cm}^{-1} \\
\mathrm{SiH}_{3}\end{array}$ & $\begin{array}{l}2180 \\
\mathrm{~cm}^{-1} \\
\mathrm{OSiH}_{2}\end{array}$ & $\begin{array}{l}2240 \\
\mathrm{~cm}^{-1} \\
\mathrm{OOSiH}_{2}\end{array}$ & & \\
\hline 32 & 20 & 10 & 7 & - & - & 7 & 2.4 & 3 \\
\hline 33 & 40 & 9 & 33 & - & 7 & 10 & 2.0 & 8.4 \\
\hline 34 & 60 & 15 & 30 & 2 & 5 & 7 & 2.1 & 5.9 \\
\hline 35 & 80 & 10 & 40 & 7 & 15 & 25 & 2.2 & 8.6 \\
\hline
\end{tabular}

Hydrogen flow rate, 10 standard $\mathrm{cm}^{3} \mathrm{~s}^{-1}$. 
exhibits an increase in the $\mathrm{SiH}$ peak at $2000 \mathrm{~cm}^{-1}$, indicating that the $\mathrm{SiH}$ is indeed located in the bulk material. An additional peak at $2085 \mathrm{~cm}^{-1}$ arises and no oxidation occurs. The deposition rate is about $3 \mathrm{~nm} \mathrm{~s}^{-1}$ and the pseudo index of refraction is 2.65 . The surface roughness of this sample is considerable, as can be seen in Fig. 8.

In the following experiment, we increased the hydrogen flow from 10 standard $\mathrm{cm}^{3} \mathrm{~s}^{-1}$ to 40 standard $\mathrm{cm}^{3} \mathrm{~s}^{-1}$ and treated the sample after deposition for $5 \mathrm{~min}$ with an argon-hydrogen beam. The increase in hydrogen flow is performed to investigate a possible restructuring of the growing film. In Fig. 9 the surface structure can be seen as well as a side view of the sample obtained at an original magnification of $10000 \times$. The hydrogen-argon beam apparently removes the

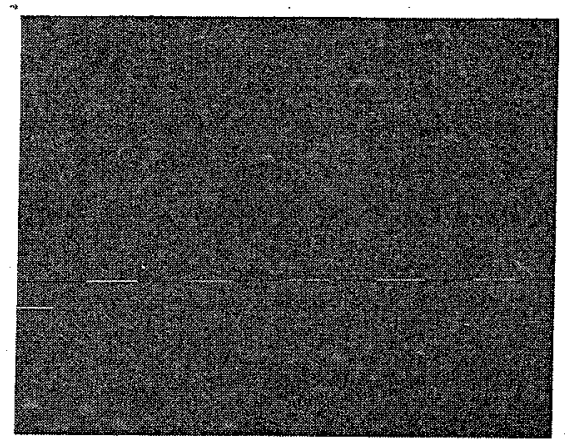

Fig. 7. SEM micrograph of sample 35. The white bar represents $1 \mu \mathrm{m}$.
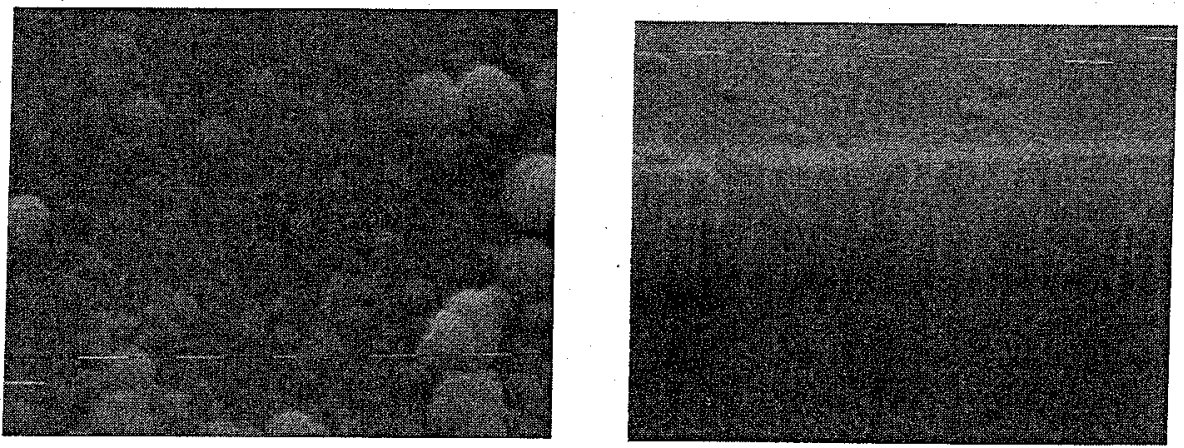

Fig. 8. SEM micrograph of sample 36. The surface roughness is considerable. The white bar represents $1 \mu \mathrm{m}$.

Fig. 9. SEM micrograph of sample 37 (hydrogen flow rate, 40 standard $\mathrm{cm}^{3} \mathrm{~s}^{-1}$ ). After the deposition a hydrogen-argon plasma is directed onto the film. The white bar represents $1 \mu \mathrm{m}$.

surface roughness from the film after the deposition has taken place. In Table VI the oscillator strengths, the refractive indices and the deposition rates of this sample and the corresponding sample $(60 \mathrm{~A})$ from the previous series are shown. As can be seen from the table, a strong $\mathrm{SiH}$ peak is present together with a peak at $2085 \mathrm{~cm}^{-1}$. There is no sign of oxidation in the sample produced with the high hydrogen flow.

Although the strength of the SiH stretch mode has increased compared with the 
TABLE VI

OSCILLATOR STRENGTHS, PSEUDO REFRACTIVE INDICES AND DEPOSITION RATES OF THE SAMPLE PRODUCED WITH HIGH HYDROGEN FLOW AND THE CORRESPONDING SAMPLE FROM THE PREVIOUS SERIES

\begin{tabular}{|c|c|c|c|c|c|c|}
\hline \multirow[t]{2}{*}{ Sample } & \multirow{2}{*}{$\begin{array}{l}\mathrm{H}_{2} \\
\text { (standard } \\
\mathrm{cm}^{3} \mathrm{~s}^{-1} \text { ) }\end{array}$} & \multicolumn{3}{|c|}{ Oscillator strengths of the following peaks $\left(\times 10^{-4}\right)$} & \multirow{2}{*}{$\begin{array}{l}\text { Index } \\
-\quad\left(\mathrm{nm} \mathrm{s}^{-}\right.\end{array}$} & \multirow{2}{*}{$\begin{array}{l}\text { Rate } \\
\text {-1) }\end{array}$} \\
\hline & & $\begin{array}{l}2000 \\
\mathrm{~cm}^{-1} \\
\mathrm{SiH}\end{array}$ & $\begin{array}{l}2085 \\
\mathrm{~cm}^{-1} \\
?\end{array}$ & $\begin{array}{l}2100 \\
\mathrm{~cm}^{-1} \\
\mathrm{SiH}_{2}\end{array}$ & & \\
\hline 34 & 10 & 15 & - & 30 & 2.1 & 5.9 \\
\hline 37 & 40 & 15 & 50 & - & 2.7 & 3 \\
\hline
\end{tabular}

The first sample had been treated after production with a hydrogen-argon beam for $5 \mathrm{~min}$.

previous series, the refractive index is still too low. The hydrogen injection quenches the expanding argon beam too heavily. Also, the injection of the silane gas is too far downstream of the start of the expansion. We moved the injection of the silane gas further upstream, directed upstream into the shock. The hydrogen gas is now injected in the middle of the argon arc. The hydrogen is heated by the active plasma. The dissociation of the molecular hydrogen in the arc is almost complete and the lowering of the degree of ionization in the expansion should be smaller than in the case of injection in the nozzle because the partial pressure of residual molecular hydrogen will be less. The rest of the experimental conditions are kept the same as in the previous measurement. To monitor the deposition, in situ $\mathrm{Hu}-\mathrm{Ne}$ ellipsometry is used. The in situ ellipsometry eliminates any possible effects due to native oxides when the films are exposed to air. Analysis of the He-Ne ellipsometry data revealed the following results. The deposition rate was $3.9 \mathrm{~nm} \mathrm{~s}^{-1}$. The refractive index of the film is 3.75 at $632 \mathrm{~nm}$ and the extinction coefficient is 0.15 . This complex refractive index is obtained after correcting the ellipsometric data for possible sublayers and top layers. In this case no sublayer could be detected. The silicon substrate has been dipped with HF before the deposition experiment and is cleaned with an argon plasma beam. The top layer has a thickness of approximately $10 \mathrm{~nm}$, a refractive index of 1.5 and an extinction coefficient of 0.1 . With SEM analysis no surface structure could be detected using a magnification of $20000 \times$ and a spot size of $16 \mathrm{~nm}$. The smallest structure which could have been distinguished using this magnification is $50 \mathrm{~nm}$. The thickness of the top layer is different from that of the top layers observed on films obtained in PECVD experiments ${ }^{25,26}$. This is probably due to a difference in the kinetics of the growth of the film, caused by the difference in particle flux composition and the ion bombardment energy.

A Bruker IR interferometer was used to analyse the $\mathrm{SiH}_{n}$. bonds in the wavenumber range from 3000 to $400 \mathrm{~cm}^{-1}$. The IR analysis showed absorptions at 2000 and $2085 \mathrm{~cm}^{-1}$ of equal strength. Compared with the previous series, this is a decrease in the absorption at $2085 \mathrm{~cm}^{-1}$ relative to the absorption at $2000 \mathrm{~cm}^{-1}$ by more than a factor of 3 .

In the literature, the nature of the IR vibrational absorption peak at the frequency of $2085 \mathrm{~cm}^{-1}$ is not completely clear. It is attributed to $\mathrm{SiH}$ as well as to $\mathrm{SiH}_{2}$. Shanks et al. ${ }^{27}$ and $\mathrm{Paul}^{28}$ state that the absorption at $2085 \mathrm{~cm}^{-1}$ can be 
attributed to $\mathrm{SiH}$. The $\mathrm{SiH}$ molecules which cause this absorption are present in pairs or quartets located in a small void opposed to each other. If the $2085 \mathrm{~cm}^{-1}$ peak is caused by $\mathrm{SiH}_{2}$, then the $890 \mathrm{~cm}^{-1}$ peak due to the bending mode of $\mathrm{SiH}_{2}$ should also be present. $\mathrm{SiH}$ has no bending modes. To check this, we performed IR transmission interferometry ${ }^{29}$ in the wavenumber range from 800 to $2200 \mathrm{~cm}^{-1}$. Therefore we deposited the last series of samples not only on silver or gold substrates but also on silicon wafers. The layer thickness typically ranges from $300 \mathrm{~nm}$ to $3 \mu \mathrm{m}$. We measured the absorption of the deposited layer. The sensitivity of the instrument imposes a minimum thickness of the film $(1.5 \mu \mathrm{m})$. Sample 37 has a thickness of $2 \mu \mathrm{m}$. The vibrational absorption peaks measured with the spectroscopic ellipsometer also clearly show in the spectrum measured with the IR transmission interferometer. There. is, however, no trace of the $890 \mathrm{~cm}^{-1}$ absorption peak. It is therefore reasonable to assign the $2085 \mathrm{~cm}^{-1}$ peak to $\mathrm{SiH}$.

The strength of the absorption peak at $2085 \mathrm{~cm}^{-1}$ in the last sample is approximately equal to the strength of the absorption peak at $2000 \mathrm{~cm}^{-1}$. However, the absorption constant $A$ for the peak at $2085 \mathrm{~cm}^{-1}$ is eight times stronger $\left(A_{2085}=17 \times 10^{17} \mathrm{~cm}^{-2}, A_{2000}=2.2 \times 10^{17} \mathrm{~cm}^{-2}\right)^{8}$. Therefore the majority of the $\mathrm{SiH}_{n}$ bonds are $\mathrm{SiH}$ bonds.

\section{CONCLUSIONS}

We have analysed the first a-Si:H samples produced with an expanding arc plasma with spectroscopic ellipsometry. Several conclusions can be drawn from these preliminary measurements. The optimum substrate temperature for depositing stable films is the same as in CVD techniques, between 500 and $600 \mathrm{~K}$. The film properties are associated with the degree of ionization of the expanding argon beam which is directly coupled to the composition and the temperature of the plasma. At lower temperatures of the plasma beam, the resulting films are dominated by the presence of $\mathrm{SiH}_{2}$. With increasing temperature, the hydrogen content of the film decreases considerably and the refractive index approaches the value of amorphous silicon.

Introduction of molecular hydrogen into the expansion to increase the hydrogen content of the films quenches the plasma expansion severely. With decreasing temperature and electron density, the dissociating power of the plasma beam decreases strongly. The film obtained has a high refractive index only under conditions where the deposition rate is relatively low. With increasing plasma temperature the $\mathrm{SiH}_{2}$ bond dominates. The films oxidize after exposure to air. Reduction in distance between substrate and arc from 0.85 to $0.5 \mathrm{~m}$ only enhances this effect and the $\mathrm{SiH}_{2}$ content of the films increases further. Introduction of more hydrogen (from 10 to 40 standard $\mathrm{cm}^{3} \mathrm{~s}^{-1}$ ) increases the refractive index and enhances the strength of the $\mathrm{SiH}$ bond compared with the $\mathrm{SiH}_{2}$ bond. Injection of hydrogen in the middle of the burning arc enhances the dissociation of the hydrogen molecules and reduces the decrease in the electron density of the expanding plasma beam. This resulted in a film with a refractive index at $632 \mathrm{~nm}$ of 3.75 . The increase in the vibrational absorption of $\mathrm{SiH}$ stretch mode and decrease in the vibrational absorption of the $\mathrm{SiH}_{2}$ stretch mode indicate together with the higher refractive 
index a densification of the film. The value of the refractive index is still too low compared with that for high quality material obtained with $\operatorname{PECVD}^{15}$.

The stable films contain absorptions at $2000 \mathrm{~cm}^{-1}$ and $2085 \mathrm{~cm}^{-1}$. In PECVD produced films, only the $2000 \mathrm{~cm}^{-1}$ absorption peak is present. Hiraki et al. ${ }^{30}$ showed that if the $2100 \mathrm{~cm}^{-1}$ peak $\left(\mathrm{SiH}_{2}\right)$ is present in their crystalline hydrogenated silicon samples severe degradation of the photoconductivity occurs if the samples are exposed to air and oxidation peaks appear. If, however, the $2085 \mathrm{~cm}^{-1}$ absorption peak occurs, the photoconductivity is unaffected after air exposure and no oxidation peaks appear.

In general, the structure of the obtained a-Si:H films is close to the structure as observed in PECVD material. Still, further optimization has to be performed regarding the silane injection into the expanding beam, the silane concentration and the flow of hydrogen. Future analysis will also include photoconductivity and dark conductivity measurements.

\section{ACKNOWLEDGMENTS}

We should like to thank C. J. Timmermans, A. B. M. Husken, L. Bisschops and T. Bisschops who took part in the design, realization and operation of the deposition system and sample production. Also, we would like to thank C. J. H. M. Poorts who analysed the in situ $\mathrm{He}-\mathrm{Ne}$ ellipsometry data. This work is part of the research program of the Stichting voor Fundamenteel Onderzoek der Materie (FOM), which is financially supported by the Nederlandse Organisatie voor Wetenschappelijk Onderzoek (NWO).

\section{REFERENCES}

I J. Mort and F. Jansen, Plasma-deposited Thin Films, CRC Press, Boca Ration, FL, 1986.

2 G. M. W. Kroesen, D. C. Schram and M. J. F. van de Sande, Plasma Chem. Plasma Process, 10 (1990) 49 .

3 J. J. Beúlens, G. M. W. Kroesen, D. C. Schram, C. J. Timmermans, P. C. N. Crouzen, H. Vasmel, H. J. A. Schuurmans, C. B. Beijer and J. Werner, J. Appl. Polym. Sci., 46 (1990) 527.

4 P. K. Bachmann, H. Lydtin, P. U. Wychert, J. J. Beulens, G. M. W. Kroesen and D. C. Schram, Proc. 3rd Int. Conf. on Surface Modification Technologies, Neuchâtel, September 1989, The Minerals, Metals and Materials Society, Warrendale, PA, 1990, p. 69.

5 A. J. M. Buuron, J. J. Beulens, M. J. F. van de Sande and D. C. Schram, Proc. 5 th Workshop on Carbon Materials, Forschungszentrum Jülich, Mav 17-18, 1990, Fusion Technol, to be published.

6 T. Ohwaki and Y. Taga, Appl. Phys. Lett., 55 (9) (1989) 837.

7 J. J. Beulens, M. S. de Wit, Y. L. M. Creyghton, G. M. W. Kroesen, C. J. Timmermans and D. C. Schram, Proc. 3rd Int. Conf. on Surface Modification Technologies, Neuchâtel, September 1989, p. 17.

8. M. Cardona, Phys. Status solidi B, $118(1983) 463$.

9 S. R. Elliot, Adv. Phys., 38 (1) (1989) 1-88.

10 J. D. Joannopoulos and G. Lucovsky, The Physics of Hydrogenated Amorphous Silicon II, Electronic and Vibrational Properties, Springer, Berlin, 1984.

11 J.I. Pankove, in J. I. Pankove (ed.). Semiconductors and Semimetals: Hydrogenated Amorphous Silicon, Vol. 2 la-2Id, Academic Press, New York, 1984.

12 H. Fritzsche, Amorphous Silicon and Related Materials, Vol. 1, World Scientific Press, Singapore, 1989.

13 B. Drevillon and R. Benferhat, J. Appl. Phys., 63 (10) (1988) 5088. 
14 R. Benferhat, B. Drevillon and P. Robin, Thin Solid Films, 156 (1988)) 295.

15 D. E. Aspnes, A. A. Studna and E. Kinsbron, Phys. Rev. B, 29 (1984) 768.

16 G. M. W. Kroesen, A. T. M. Wilbers, M. J. F. van de Sande, D. C. Schram, L. A. Bisschops, C. J. Timmermans, H. J. Heller and A. B. M. Husken, Internal Rep. VDF/NT 90-06, 1990 (Eindhoven University of Technology).

17 E. Nygren, B. Park, L. M. Goldman and F. Spaepen, Appl. Phys. Lett., 56 (21) (1990) 2094.

18 G. J. Meeusen, A. T. M. Wilbers, C. J. Timmermans, L. A. Bisschops, A. B. M. Hüsken, T. H. J. Bisschops and D. C. Schram, to be published.

19 G. M. W. Kroesen, G. S. Oehrlein, E. de Fresart and M Haverlag, to be published.

20 G. M. W. Kroesen, S. de Wit, A. T. M. Wilbers and Y. L. M. Creyghton, to be published.

21 A. T. M. Wilbers, G. M. W. Kroesen, C. J. Timmermans and D. C. Schram, Meas. Sci. Tec/mol. I (1990) 1326.

22 M. J. de Graaf, R. P. Dahiya, J. L. Jauberteau, F. J. de Hoog, M. J. F. van de Sande and D. C. Schram, J. Phys. ( Puris), Colloq. C5, 51 (1990) 387.

23 R. Messier and J. E. Yehoda, J. Appl. Phvs., 58 (1985) 3739

24 R. Messier, J. Vac. Sci. Technol. A, 4(1986) 490.

25 A. M. Antoine, B. Drevillon and P. Roca i Cabarrocas, J. Appl. Phys., 61 (1987) 2501.

26 R. W. Collins and A. Pawlowski, J. Appl. Phys., 59 (1986) 1160.

27 H. Shanks, C. J. Fang, L. Ley, M. Cardona, F. J. Demond and S. Kalbitzer, Phıs. Status Solidi B, I00 (1980) 43.

28. W. Paul, Solid State Comntum., 34 (1980) 283-285.

29 M. Haverlag, G. M. W. Kroesen and F. J. de Hoog, Proc. 9th Int. Symp. on Plasma Chemistry, Pugnochiuso, 1989, International Union of Pure and Applied Chemistry, Pugnochiuso, Italy, 1989, p. 441 .

30 A. Hiraki, T. Imura, K. Mogi and M. Tashiro, J. Phys. (Paris), Colloq. C4, 42 (1981) 277. 